\title{
STUDI BUKAAN MULUT LARVA KERAPU SUNU (PLECTROPOMUS LEOPARDUS) DAN KESESUAIAN UKURAN PAKAN ALAMI
}

\author{
Sudewi*, Yasmina Nirmala Asih, dan Afifah Nasukha \\ Balai Besar Riset Budidaya Laut dan Penyuluhan Perikanan (BBRBLPP) \\ Dusun Gondol, Desa Penyabangan, Kecamatan Gerokgak, Kabupaten Buleleng, Bali, Indonesia \\ *Koresponden penulis : dewigrim@gmail.com
}

\begin{abstract}
Abstrak
Data mengenai bukaan mulut larva kerapu sunu Plectropomus leopardus merupakan hal penting dalam memilih pakan alami yang sesuai selama pemeliharaan larva. Oleh karena itu, studi ini bertujuan untuk mengetahui ukuran bukaan mulut larva dari D-3 hingga D-30, dan mengevaluasi kesesuaian ukuran pakan alami untuk larva. Larva kerapu sunu dipelihara selama 30 hari dan diberi pakan trochophore sejak hari ke-dua (D-2), rotifer pada D-3, nauplii kopepoda mulai hari ke-4 dan nauplii Artemia sejak D-20. Sampling dilakukan terhadap minimal 30 individu untuk dilakukan pengambilan gambar dan pengukuran baik bukaan mulut larva maupun pakan alami. Bukaan mulut larva meningkat secara lambat mulai dari D$3(113,33 \pm 29,85 \mu \mathrm{m}) \mathrm{ke} \mathrm{D}-7(144,65 \pm 23,99 \mu \mathrm{m})$, tetapi meningkat secara signifikan ke 263,67 $\pm 44,57 \mu \mathrm{m}$ pada D-10 dan berturut-turut pada D-20 dan D-30 yaitu 470,94 $\pm 123,86 \mu \mathrm{m}$ dan 719,73 $\pm 103,39 \mu \mathrm{m}$. Hasil pengamatan menunjukkan bahwa trochophore sesuai untuk larva D-2 karena ukurannya lebih rendah dari

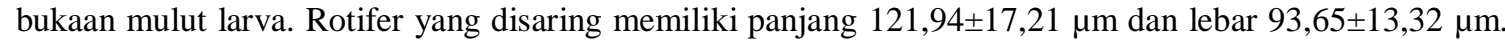
Penting untuk diperhatikan bahwa hanya 34,14\% (14/41) dari populasi rotifer memiliki panjang dibawah bukaan mulut larva D-3. Rata-rata panjang dan lebar nauplii kopepoda yaitu $354,40 \pm 44,83 \mu \mathrm{m}$ dan 237,77 $\pm 33,42 \mu \mathrm{m}$ mengindikasikan bahwa ukuran ini jauh lebih tinggi dari bukaan mulut larva D-4. Nauplii Artemia memiliki rata-rata panjang 541,23 $\pm 88,56 \mu \mathrm{m}$ dan lebar 408,62 $\pm 68,25 \mu \mathrm{m}$, sebagai konsekuensinya, larva D-20 tidak dapat memangsa dari sisi samping, tetapi dapat memangsa nauplii Artemia dari arah depan. Kami menyarankan bahwa prinsip kesesuaian ukuran pakan alami sebaiknya diterapkan dalam pemeliharaan larva kerapu sunu (P. leopardus) untuk meningkatkan pemangsaan pakan alami oleh larva.
\end{abstract}

Kata Kunci: bukaan mulut, pakan alami, larva kerapu sunu, Plectropomus leopardus

\begin{abstract}
Data on the mouth gap of coral trout grouper Plectropomus leopardus larvae is vital on selecting their suitable live feed during its larval rearing. Therefore, this study was aimed to determine the mouth gap of the larvae as well as to evaluate the compatibility of its live feed. P. leopardus larvae were reared for 30 days and fed on trochophore since day-2 (D-2), rotifers started on D-3, copepods nauplii on D-4, and Artemia nauplii which started on D-20. A minimum of 30 larvae and each type of the live feed were sampled, photographed, and measured for their size. Mouth gap of the larvae increased slowly from D-3 $(113.33 \pm 29.85 \mu \mathrm{m})$ to $\mathrm{D}-7(144.65 \pm 23.99 \mu \mathrm{m})$, but rose significantly to $263.67 \pm 44.57 \mu \mathrm{m}$ on $\mathrm{D}-10$, $470.94 \pm 123.86 \mu \mathrm{m}$ and $719.73 \pm 103.39 \mu \mathrm{m}$ on $\mathrm{D}-20$ and $\mathrm{D}-30$, respectively. Results showed that trochophore had small size, and were suitable for the larvae. The screened rotifers had an average length of $121.94 \pm 17.21 \mu \mathrm{m}$ and width of $93.65 \pm 13.32 \mu \mathrm{m}$. It is important to note that only $34.14 \%(14 / 41)$ of the rotifers revealed length under the mouth gap of D-3 larvae. The mean length and width of copepods nauplii were $354.40 \pm 44.83 \mu \mathrm{m}$ and $237.77 \pm 33.42 \mu \mathrm{m}$ indicated that this size was much higher than the mouth gap of D-4 larvae. Artemia nauplii showed an average length of $541.23 \pm 88.56 \mu \mathrm{m}$ and width of 408.62 $\pm 68.25 \mu \mathrm{m}$ implied that D-20 larvae could not prey from the lateral side, but they can prey from the anterior part of Artemia nauplii. We suggested that the compatibility concept should be adopted in P. leopardus larval rearing to increase live feed predation by the larvae.
\end{abstract}

Keywords: mouth gap, live feed, coral trout, Plectropomus leopardus larvae 


\section{PENDAHULUAN}

Kerapu sunu, Plectropomus leopardus merupakan ikan laut yang memiliki pasar domestik maupun ekspor yang luas dengan harga tinggi terutama jika dijual dalam keadaan hidup [1, 2, 3]. Ikan kerapu yang diperjualbelikan saat ini sebagian besar berasal dari penangkapan di alam [1]. Oleh karena itu diperlukan pembenihan untuk mengantisipasi kebutuhan benih dan permintaan pasar. Untuk memenuhi kebutuhan pasar, domestikasi kerapu sunu di Balai Besar Riset Budidaya Laut dan Penyuluhan Perikanan (BBRBLPP) Gondol sudah dilakukan sejak 2003 [4, 5].

Teknologi pembenihan kerapu sunu dikembangkan dengan mengadopsi teknologi pembenihan spesies kerapu yang lain. Namun, hingga saat ini ketersediaan benih kerapu sunu belum stabil. Tingginya kematian masih sering terjadi pada tahap pemeliharaan larva [3]. Sintasan yang rendah yaitu $0,11-0,46 \%$ dilaporkan pada tahun 2004 [6] dan 1,4\% tahun 2012 [7]. Tinggi rendahnya sintasan salah satunya dipengaruhi oleh kemampuan larva pada awal pemangsaan yang disebabkan oleh kurang sesuainya ukuran sediaan pakan alami dengan perkembangan larva [4].

Jenis pakan awal yang sesuai merupakan faktor penentu keberhasilan dalam pemeliharaan larva. Pakan alami jenis larva tiram (trochophore), rotifer dari jenis Brachionus rotundiformis dan emulsi kuning telur telah dicoba dalam penelitian sebagai pakan awal untuk larva. Emulsi kuning telur mampu meningkatkan pertumbuhan dan sintasan larva [4]. Jasad pakan alami yang lain seperti nauplii kopepoda dari jenis Acartia sp, serta nauplii Artemia.

Sehubungan dengan pentingnya untuk memilih jenis pakan alami yang sesuai untuk larva, terutama dalam hal ukuran, maka data bukaan mulut larva kerapu sunu Plectropomus leopardus perlu diketahui untuk keberhasilan pembenihan. Hingga saat ini, bukaan mulut larva hanya diketahui untuk D-3 larva yaitu 145-150 $\mu \mathrm{m}$ [4]. Oleh karena itu, penelitian ini dilakukan untuk mengetahui ukuran bukaan mulut larva, D-3 hingga D-30, serta evaluasi kesesuaian ukuran pakan alami untuk pemeliharaan larva kerapu sunu.

\section{MATERI DAN METODE}

\section{Pemeliharaan larva}

Penelitian dilakukan di hatcheri kerapu sunu BBRBLPP, Gondol, Bali tahun 2018. Pemeliharaan larva menggunakan bak beton berkapasitas $6 \mathrm{~m}^{3}$ dengan dinding bagian dalam berwarna kuning, diisi air dengan volume $5 \mathrm{~m}^{3}$. Bak beton diisi air laut $(33 \pm 1$ ppt), dilengkapi dengan aerasi yang posisinya diatur secara merata. Penebaran telur kerapu sunu 50.000-100.000 butir/bak. Larva menetas setelah 1 hari dari penebaran telur. Pemberian pakan dilakukan setelah cadangan makanan (egg yolk) terserap habis dan mulut larva telah terbuka yaitu dua hari setelah menetas.

Pemberian fitoplankton Nannochloropsis ocullata yang berasal dari kultur massal dilakukan pada pagi hari dan dimulai pada hari ke-dua [8, 7]. Fitoplankton diberikan sebagai green water sekaligus sebagai pakan untuk rotifer. Larva tiram (trochophore) diberikan pada pagi hari (D2-D10) [4, 9]. Sedangkan pemberian rotifer $B$. rotundiformis dilakukan mulai pada umur larva tiga hari (D3) $[8,7,10]$, nauplii kopepoda sejak D-4 dan nauplii Artemia mulai diberikan pada D20 hingga fase benih [4].

\section{Sampling larva dan pakan alami}

Pengukuran bukaan mulut larva dilakuan setiap hari dimulai $\mathrm{D}-3$ hingga $\mathrm{D}-10$, setiap 2 hari hingga D-20, kemudian D-25 dan D-30. Pengukuran sampel larva, trochophore, rotifer, kopepoda dan Artemia dilakukan terhadap minimal sebanyak 30 individu [11].

Pengamatan dilakukan menggunakan mikroskop, pengambilan gambar dengan ACT program dan pengukuran bukaan mulut larva dan pakan alami menggunakan WinRoof program. Data dianalisis secara deskriptif menggunakan histogram dengan program $\mathrm{R}$ statistic ( $\mathrm{R}$ commander package).

\section{HASIL DAN PEMBAHASAN}

\section{Perkembangan bukaan mulut larva}

Perkembangan bukaan mulut larva kerapu sunu ditunjukkan pada Gambar 1. Ukuran bukaan mulut larva meningkat secara lambat dari D-3 $(113,33 \pm 29,85 \mu \mathrm{m})$ ke D-7 $(144,65 \pm 23,99 \mu \mathrm{m})$, tetapi meningkat secara tajam pada D-10 $(263,67 \pm 44,57 \mu \mathrm{m}), \mathrm{D}-20$ 
$(470,94 \pm 123,86$

$\mu \mathrm{m})$

dan

D-30

$(719,73 \pm 103,39 \mu \mathrm{m})($ Gambar 2).

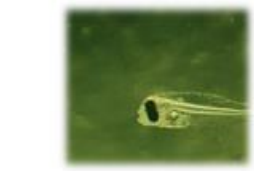

D-3

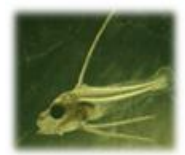

D-14

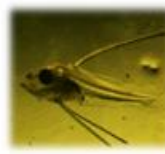

D-16

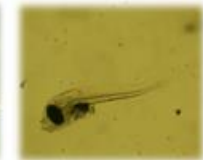

D-6

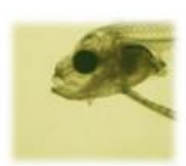

D-20
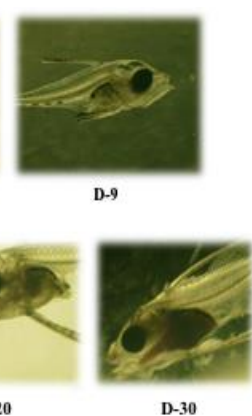

Gambar 1 Perkembangan bukaan mulut larva kerapu sunu (Plectropomus leopardus) dari hari ke-tiga (D-3) hingga hari ke-tiga puluh (D-30).

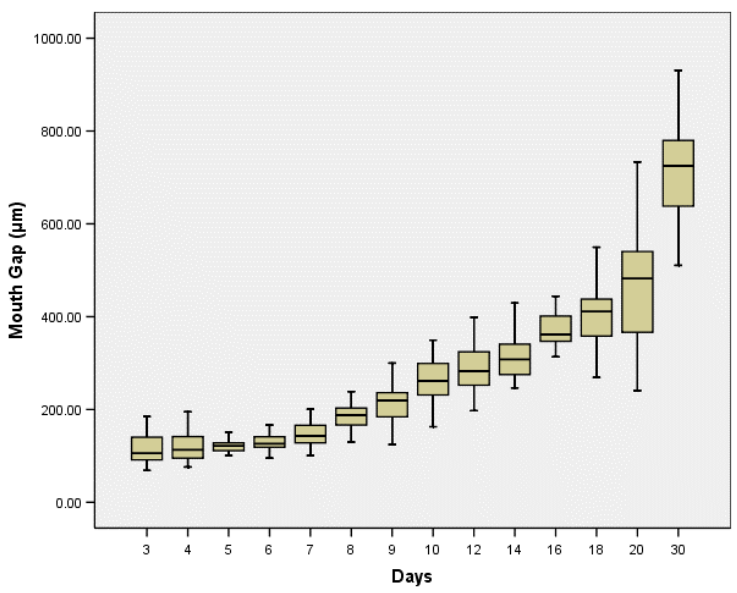

Gambar 2 Grafik perkembangan ukuran bukaan mulut larva kerapu sunu (Plectropomus leopardus) dari hari ke-tiga (D-3) hingga hari ke-tiga puluh (D-30).

Hasil penelitian ini menunjukkan bahwa bukaan mulut larva D-3 yaitu $113,33 \pm 29,85$ $\mu \mathrm{m}$, lebih kecil dari penelitian sebelumnya di BBRBLPP yaitu 120-170 $\mu \mathrm{m}$ [8]. Perkembangan bukaan mulut larva kerapu sunu berkorelasi secara linear dengan panjang total larva (Gambar 3). Bukaan mulut larva bertambah seiring dengan pertambahan panjang total larva, dengan persamaan $\mathrm{y}=$ $0,0782 \mathrm{x}-33,557$.

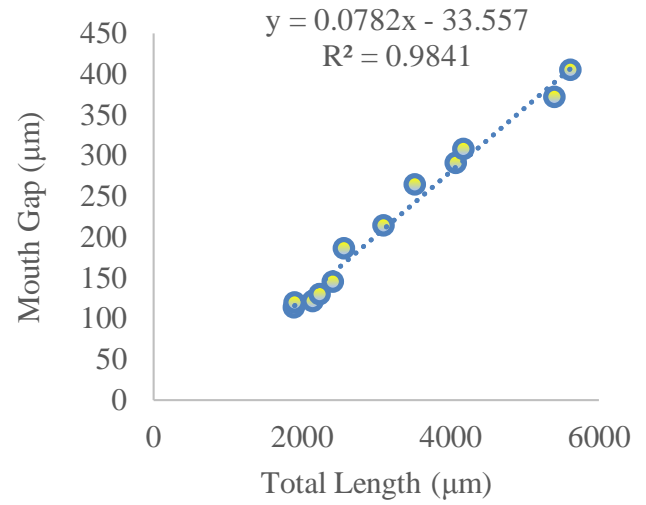

Gambar 3 Hubungan panjang total dengan perkembangan bukaan mulut larva kerapu sunu (Plectropomus leopardus).

\section{Evaluasi kesesuaian ukuran trochophore}

Pengukuran bukaan mulut larva dalam penelitian ini dilakukan mulai pada larva D-3, tidak mulai dari D-2 karena larva D-2 baru mulai membuka mulutnya dan belum semua larva menunjukkan bukaan mulut. Oleh karena itu, ukuran trochophore dalam penelitian ini dibandingkan dengan bukaan mulut larva D-3, meskipun trochophore diberikan pada larva sejak D-2. Trochophore yang digunakan sebagai pakan larva memiliki ukuran panjang $=46,67 \pm 5,88 \mu \mathrm{m}$ dan lebar $=41,04 \pm 3,99 \mu \mathrm{m}$. Ukuran tersebut jauh lebih kecil dari bukaan mulut larva D-3 (Tabel 1). Oleh karena itu, larva mampu memangsa trochophore yang tersedia sesuai dengan bukaan mulutnya. Ukuran trochophore dalam penelitian ini lebih kecil dari penelitian sebelumnya $(62,84 \pm 3,87 \mu \mathrm{m})[4]$.

Tabel 1. Ukuran trochophore dibandingkan dengan bukaan mulut larva D-3 kerapu sunu (Plectropomus leopardus).

\begin{tabular}{ll}
\hline Trochophore & Bukaan mulut larva D-3 \\
\hline Panjang $=46,67 \pm 5,88 \mu \mathrm{m}$ & $113,33 \pm 29,85 \mu \mathrm{m}$ \\
Lebar $=41,04 \pm 3,99 \mu \mathrm{m}$ & \\
\hline
\end{tabular}

Studi lain menyebutkan bahwa telur dan trochopore kerang banyak digunakan sebagai pakan awal dalam pembenihan kerapu karena memiliki keuntungan yaitu ukurannya lebih kecil dari bukaan mulut larva. Telur dan larva kerang Pinctada martensi digunakan sebagai pakan awal untuk kerapu sunu pada umur 5 hari, dengan laju pemangsaan mencapai $45 \%$. Akan tetapi, dalam penggunaan trochophore perlu memperhatikan waktu, jika trochophore sudah berkembang menjadi larva berbentuk 
huruf "D", maka larva tidak bisa mencernanya. Oleh karena itu, manajemen waktu pemberian trochophore sangat penting untuk diperhitungkan [12].

\section{Evaluasi kesesuaian ukuran rotifer}

Rotifer yang disaring memiliki panjang $121,94 \pm 17,21 \mu \mathrm{m}$ dan lebar 93,65 $\pm 13,32 \mu \mathrm{m}$. Sedangkan, ukuran rotifer yang tidak disaring jauh lebih besar yaitu panjang $151,77 \pm 19,47$ $\mu \mathrm{m}$ dan lebar 108,27 $\pm 21,64 \mu \mathrm{m}$ (Tabel 2). Diameter telur rotifer yang tidak disaring dan yang disaring masing-masing $68,27 \pm 10,97 \mu \mathrm{m}$ dan $64,83 \pm 11,69 \mu \mathrm{m}$. Sebanyak $48 \%$ dari populasi rotifer yang tidak disaring memiliki telur. Sebaliknya, hanya $19,10 \%$ dari populasi rotifer yang disaring membawa telur.

Tabel 2. Ukuran rotifer yang tidak disaring dan yang disaring dibandingkan dengan ukuran bukaan mulut larva D-3 kerapu sunu (Plectropomus leopardus)

\begin{tabular}{|c|c|c|c|}
\hline & $\begin{array}{l}\text { Rotifer tidak } \\
\text { disaring }\end{array}$ & $\begin{array}{l}\text { Rotifer } \\
\text { disaring }\end{array}$ & $\begin{array}{l}\text { Bukaan mulut } \\
\text { larva D-3 }\end{array}$ \\
\hline $\begin{array}{l}\text { Panjang } \\
(\mu \mathrm{m})\end{array}$ & $151,77 \pm 19,47$ & $121,94 \pm 17,21$ & \multirow[t]{6}{*}{$\begin{array}{l}113,33 \pm 29,85 \\
\mu \mathrm{m}\end{array}$} \\
\hline Lebar $(\mu \mathrm{m})$ & $108,27 \pm 21,64$ & $93,65 \pm 13,32$ & \\
\hline $\begin{array}{l}\text { Diameter } \\
\text { telur }(\mu \mathrm{m})\end{array}$ & $68,27 \pm 10,97$ & $64,83 \pm 11,69$ & \\
\hline $\begin{array}{l}\text { Rotifer } \\
\text { membawa } \\
2 \text { telur }(\%)\end{array}$ & 40 & 12,69 & \\
\hline $\begin{array}{l}\text { Rotifer } \\
\text { membawa } \\
1 \text { telur }(\%)\end{array}$ & 8 & 7,31 & \\
\hline $\begin{array}{l}\text { Tidak } \\
\text { membawa } \\
\text { telur }(\%)\end{array}$ & 52 & 80,48 & \\
\hline
\end{tabular}

Satu hal penting perlu diketahui bahwa hanya sekitar $30 \%$ dari populasi rotifer yang disaring memiliki ukuran panjang dibawah bukaan mulut larva D-3 (Gambar 4). Sebagian besar populasi rotifer $(70 \%)$ tidak dapat dimanfaatkan oleh larva D-3. Studi sebelumnya melaporkan bahwa ukuran rotifer sebagai pakan awal yang ada di BBRBLPP, Gondol sebesar 140-200 $\mu \mathrm{m}$ (tipe S) [4]. Dengan demikian, pakan rotifer yang tersedia tidak bisa dimanfaatkan oleh larva D-3 karena terlalu besar. Rotifer yang lebih sesuai untuk bukaan mulut larva D-3 adalah tipe SS, namun kemurniannya pada kultur skala massal sulit terjaga [8]. Rotifer dalam penelitian ini disaring menggunakan saringan 115 $\mu \mathrm{m}$, oleh karena itu, disarankan untuk menggunakan saringan dengan mesh size $<90 \mu \mathrm{m}$.

Hasil pengamatan terhadap isi perut larva menunjukkan bahwa larva mulai mampu memakan rotifer pada saat berumur 5 hari. Jumlah rotifer yang termakan berkisar antara 3-10 individu. Hal ini menunjukkan bahwa larva umur 5 hari mulai mampu memangsa rotifer yang disediakan di bak pemeliharaan [13].
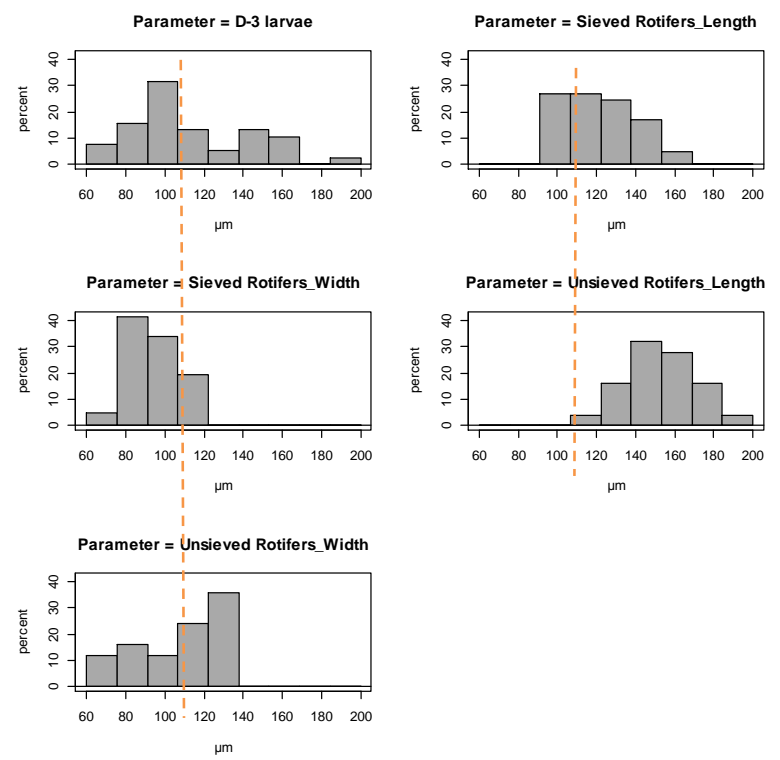

$\mu \mathrm{m}$

Gambar 3 Komposisi ukuran bukaan mulut larva kerapu sunu (Plectropomus leopardus) umur 3 hari (D-3 ; rata-rata bukaan mulut $113,33 \pm 29,85 \mu \mathrm{m}$ ), dibandingkan dengan komposisi ukuran rotifer. Garis putus-putus menunjukkan batas kesesuaian ukuran rotifer untuk larva D-3. Hanya sekitar $30 \%$ dari populasi rotifer yang disaring memiliki ukuran panjang dibawah bukaan mulut larva D-3.

\section{Evaluasi kesesuaian ukuran nauplii kopepoda}

Rata-rata panjang dan lebar kopepoda adalah $354,40 \pm 44,83 \mu \mathrm{m}$ dan $237,77 \pm 33,42$ $\mu \mathrm{m}$ (Tabel 3) mengindikasikan bahwa ukuran ini jauh lebih tinggi dari bukaan mulut larva D-4 $(119,29 \pm 29,42 \mu \mathrm{m})$. Oleh karena itu, kopepoda sebaiknya disaring menggunakan saringan $115 \mu \mathrm{m}$ sebelum pemberian pakan untuk memilih nauplii dengan ukuran yang lebih rendah dari ukuran bukaan mulut larva D-4.

Tabel 3. Ukuran nauplii kopepoda dibandingkan dengan ukuran bukaan mulut larva D-4 kerapu sunu, (Plectropomus leopardus)

\begin{tabular}{lll}
\hline & \multicolumn{1}{c}{$\begin{array}{c}\text { Nauplii } \\
\text { kopepoda }\end{array}$} & $\begin{array}{c}\text { Bukaan } \\
\text { mulut } \\
\text { larva D-4 }\end{array}$ \\
\hline Panjang total $(\mu \mathrm{m})$ & $354,40 \pm 44,83$ & $119,29 \pm 29$ \\
Panjang badan $(\mu \mathrm{m})$ & $211,32 \pm 44,42$ &, 42 \\
Lebar total $(\mu \mathrm{m})$ & $237,77 \pm 33,42$ & \\
Lebar badan $(\mu \mathrm{m})$ & $121,36 \pm 20,06$ & \\
\hline
\end{tabular}




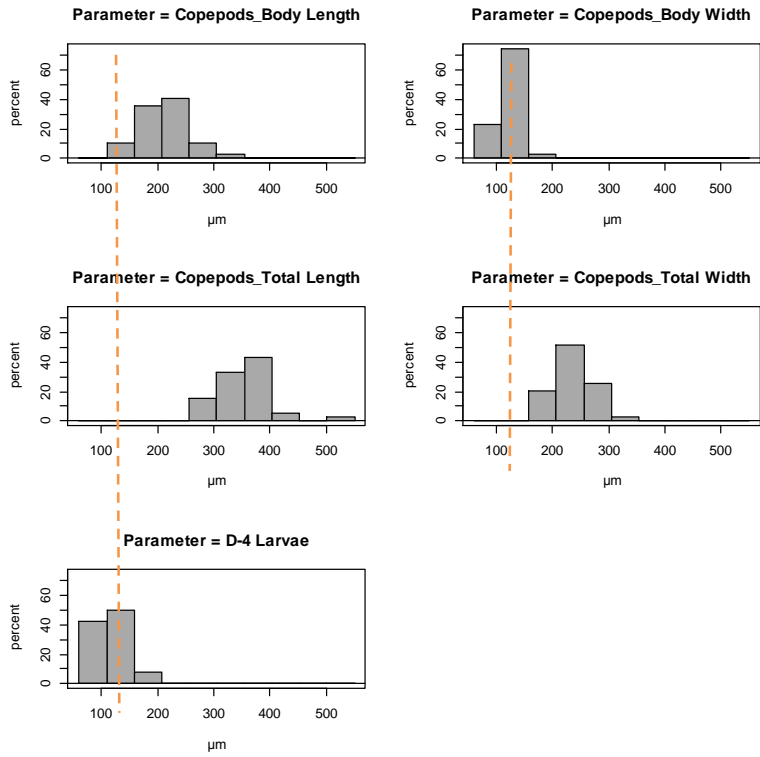

Gambar 4 Komposisi ukuran bukaan mulut larva kerapu sunu (Plectropomus leopardus) umur 4 hari (D-4 ; rata-rata bukaan mulut 119,29 $\pm 29,42 \mu \mathrm{m})$, dibandingkan dengan komposisi ukuran nauplii kopepoda. Garis putus-putus menunjukkan batas kesesuaian ukuran nauplii kopepoda untuk larva

D-4. Nauplii kopepoda memiliki ukuran lebih tinggi daripada bukaan mulut larva D-4.

Penelitian sebelumnya melaporkan bahwa naupli kopepoda mulai dimangsa oleh larva berumur 10 hari dengan lebar ukuran kopepoda sebesar $100 \mu \mathrm{m}$. Meskipun ukuran lebar bukaan mulut larva sudah bertambah, namun naupli kopepoda yang termakan masih sedikit. Hal yang sama terjadi pada larva berumur 15 hari [13]. Kopepoda yang direkomendasikan diberikan pada larva sebaiknya dari jenis harpacticoid dan acartia. Jenis cyclop pada stadia nauplii dapat diberikan, sedangkan stadia induknya sebaiknya tidak diberikan untuk larva awal, mengingat ukuran induk kopepoda yang besar [14]. Namun, induk kopepoda dapat diberikan pada larva umur 20 hari [13]. Bervariasinya ukuran dan tahapan selama siklus hidup kopepoda merupakan keuntungan dari penggunaan kopepoda sebagai pakan untuk larva dalam pembenihan berbagai jenis ikan laut [15].

\section{Nauplii Artemia}

Nauplii Artemia memiliki panjang $541,23 \pm 88,56 \mu \mathrm{m}$ dan lebar 408,62 $\pm 68,25 \mu \mathrm{m}$ (Tabel 4) mengimplikasikan bahwa larva D20 tidak dapat memangsa nauplii Artemia dari sisi samping, tetapi dapat memangsa dari arah depan nauplii Artemia. Ukuran Artemia dalam penelitian ini sesuai dengan penelitian sebelumnya yaitu $>500 \mu \mathrm{m}$ [4].

Tabel 4. Ukuran nauplii Artemia dibandingkan dengan ukuran bukaan mulut larva D-20 kerapu sunu, (Plectropomus leopardus)

\begin{tabular}{lcc}
\hline & $\begin{array}{c}\text { Nauplii } \\
\text { Artemia }\end{array}$ & $\begin{array}{c}\text { Bukaan mulut } \\
\text { larva D-20 }\end{array}$ \\
\hline $\begin{array}{l}\text { Panjang badan } \\
(\mu \mathrm{m})\end{array}$ & $541,23 \pm 88,56$ & $470,94 \pm 123,86 \mu \mathrm{m}$ \\
Lebar badan $(\mu \mathrm{m})$ & $194,36 \pm 31,22$ & \\
Lebar total $(\mu \mathrm{m})$ & $408,62 \pm 68,25$ & \\
\hline
\end{tabular}

Analisis dengan histogram menunjukkan bahwa hanya $15 \%$ dari populasi Artemia memiliki ukuran panjang dibawah bukaan mulut larva D-20 (Gambar 5). Penggunaan nauplii Artemia sebaiknya dalam fase instar I dan II [12]. Suatu studi menemukan bahwa naupli Artemia dengan ukuran $230 \mu \mathrm{m}$ dapat dimakan oleh larva kerapu sunu setelah umur 25 hari [13].
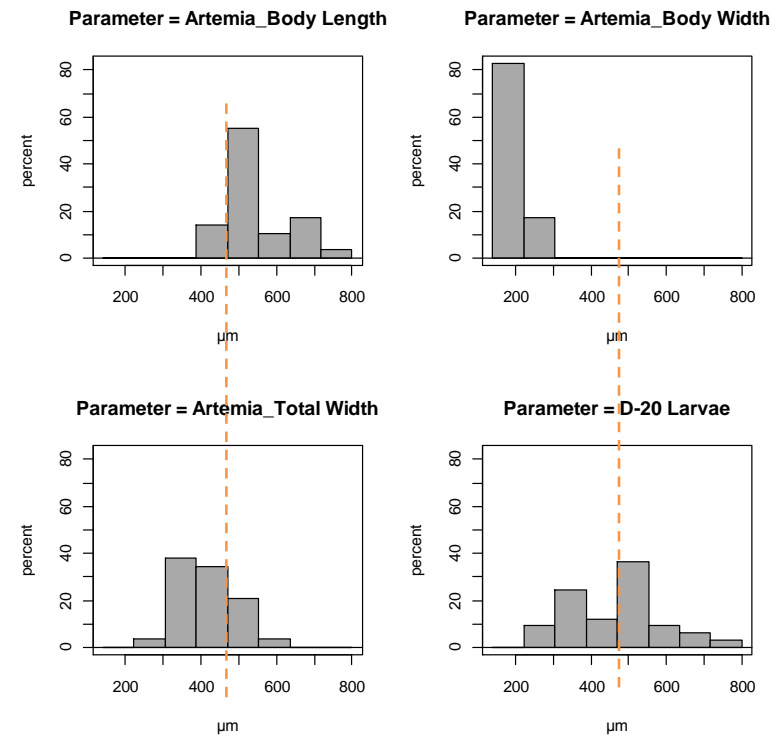

Gambar 5 Komposisi ukuran bukaan mulut larva kerapu sunu (Plectropomus leopardus) umur 20 hari (D-20 ; rata-rata bukaan mulut 470,94 $\pm 123,86$ $\mu \mathrm{m})$, dibandingkan dengan komposisi ukuran nauplii Artemia. Garis putus-putus menunjukkan batas kesesuaian ukuran Artemia untuk larva D-20. Sebagian (15\%) nauplii Artemia memiliki ukuran panjang dibawah bukaan mulut larva D-20

\section{KESIMPULAN}

Bukaan mulut larva kerapu sunu meningkat secara lambat dari D-3 ke D-7, tetapi meningkat secara tajam pada D-10, D20 dan D-30. Trochophore sesuai digunakan 
sebagai pakan larva umur D-2. Rotifer dapat diberikan untuk larva D-3, nauplii kopepoda untuk larva umur D-4 dan nauplii Artemia untuk larva D-20 dengan catatan disaring menggunakan saringan dengan mesh size dibawah ukuran bukaan mulut larva pada umur tersebut.

\section{UCAPAN TERIMA KASIH}

Terima kasih kami sampaikan kepada semua teknisi hatcheri kerapu sunu BBRBLPP Gondol atas dukungan dan bantuan selama periode pemeliharaan larva.

\section{DAFTAR PUSTAKA}

[1] K. Suwirya, A. Priyono, N. A. Giri, T. Setiadharma, "Pematangan gonad induk kerapu sunu (Plectropomus leopardus) dengan hormon LHRH-analog", Jurnal Riset Akuakutur, vol. 1, no. 3, pp. 411417, 2006.

[2] R. Andamari, "Pengaruh penambahan probiotik dan oksigen terhadap perkembangan larva kerapu sunu, Plectropomus leopardus pada stadia awal", Prosiding Forum Inovasi Teknologi Akuakultur, pp. 315-318, 2010.

[3] S. Ismi, D. Kusumawati, Y. N. Asih, "Penggunaan Nannochloropsis sp. konsentrat sebagai alternative sumber green water untuk pemeliharaan larva kerapu sunu (Plectropomus leopardus)", Prosiding Forum Inovasi Teknologi Akuakultur, pp. 561-567, 2014.

[4] T. Aslianti, K. Suwirya, dan Asmanik, "Teknologi pemeliharaan larva kerapu sunu (Plectropomus leopardus) secara massal", J. Ris. Akuakultur, vol. 3, no.1, pp. 1-11, 2008.

[5] R. Andamari, S. B. Moria, and G. N. Permana, "Aspects of leopard coral grouper (Plectropomus leopardus) reproduction in Indonesia", Indonesian Aquaculture Journal, Vol.2 No.1, pp. 51-57, 2007.

[6] R. Andamari, "Perbaikan pemeliharaan larva kerapu sunu (Plectropomus leopardus)", Prosiding Forum Inovasi Teknologi Akuakultur, pp. 13-17, 2009.

[7] R. Melianawati dan Ni Wayan W. Astuti, "Penambahan taurin melalui rotifer Brachionus rotundiformis untuk perbaikan pertumbuhan larva dan peningkatan produksi benih kerapu sunu, Plectropomus leopardus", J. Ris. Akuakultur, Vol. 7 No. 3, pp. 421-428, 2012.

[8] R. Melianawati, R. Andamari dan K. Suwirya, "Penggunaan kuning telur ayam sebagai alternatif pakan awal bagi larva ikan kerapu sunu (Plectropomus leopardus)", Aquacultura Indonesiana, vol. 7, no. 1, pp. 27-35, 2006.

[9] S. Ismi, K. Suwirya., Wardoyo, dan T. Aslianti, "Pemeliharaan larva kerapu sunu (Plectropomus leopardus) dengan kombinasi pakan awal yang berbeda. Laporan teknis hasil penelitian BBRPBL Gondol, BRSDM-KP, p 7, 2006.

[10] T. Aslianti, Asmanik, dan D. Kusumawati, "Tingkat konsumsi larva kerapu sunu, Plectropomus leopardus stadia awal pada beberapa kepadatan rotifer sebagai pakan, Prosiding Seminar Nasional Kelautan III. "Pembangunan Kelautan Berbasis IPTEK dalam Rangka Peningkatan Kesejahteraan Masyarakat Pesisir" Universitas Hang Tuah Surabaya, pp. 73-79, 24 April 2007.

[11] Y. Sawada, S. Miyashita, M. Aoyama, M. Kurata, Y. Mukai, T Okada, O. Murata, and H. Kumai, "Rotifer-Size Selectivity and Optimal Feeding Density of Bluefin Tuna, Thunnus thynnus, Larvae", Suisanzoshoku, vol. 48, no. 2, pp. 169-177, 2000.

[12] Z. Ma, H. Guo, N. Zhang, Z. Bai, "State of Art for Larval Rearing of Grouper", International Journal of Aquaculture, Vol.3, No.13, pp. 63-72, 2013.

[13] K. M. Setiawati, Ni Wayan W. Astuti, dan R. Melianawati, "Pemeliharaan 
larva kerapu sunu (Plectropomus leopardus) dengan sumber kopepoda dari budidaya dan dari tambak", Prosiding pertemuan ilmiah nasional tahunan XIII ISOI 2016 Surabaya 1 - 2 Desember 2016. pp. 216-226, 2017.

[14] D. Kusumawati, Y. N. Asih, K. M. Setiawati, "Peningkatan sintasan larva kerapu sunu Plectropomus leopardus melalui manajemen pemeliharaan yang sesuai”, Berita Biologi, Vol. 18, No. 1, pp. 59-70, 2019.

[15] R. Melianawati, Ni Wayan W. Astuti and K. Suwirya, "The Use of Copepods to Improve Juveniles Production of Coral Trout Plectropomus leopardus (Lacepède, 1802)", Middle-East Journal of Scientific Research, Vol. 16, No. 2, pp. 237-244, 2013. 